\title{
Massive Intra-Tumor Hemorrhage during Induction Chemotherapy in Neuroblastoma: A Case Series \\ Report
}

Keywords: Hemorrhage; Intra-tumoral hemorrhage; Neuroblastoma Circulatory shock

\section{Abstract}

We describe 5 children with high risk neuroblastoma (NB) who, during the induction phase of therapy, were admitted with circulatory shock because of massive intra-tumor bleeding. Patient's intensive supportive care with fluid resuscitation, blood and blood product's transfusion succeeded to restore hemodynamic stability. Surgical intervention to control bleeding was necessary in two of the children. All children survived the massive hemorrhage to continue their treatment as per protocol. Overall prognosis was not affected by this incident.

\section{Abbreviationsm}

NB:Neuroblastoma; CT: Computed Tomography; IRB: Institute Review Board; HR: High Risk

\section{Introduction}

NB is the most common extra-cranial solid tumor in children. Multiple risk factors have been identified and subsequently used in treatment protocols with the aim of increasing survival and decreasing treatment related morbidity. Treatment of NB is multi-disciplinary and active measures are used to ensure un-interrupted therapy. At presentation and before initiation of chemotherapy CT scan in some children shows intra-tumor single or multiple foci of hemorrhage [1]. On rare occasions young infants with NB present with acute massive hemorrhage that result from spontaneous tumor rupture or follows minimal trauma $[2,3]$. Acute massive hemorrhage without tumor rupture however, is an exceptional event. Over the preceding 10 years we encountered few cases of $\mathrm{NB}$ who presented with massive hemorrhage shortly after initiation of their chemotherapy protocol and their tumor on CT scan remained intact. The aim of our report is to bring into attention this peculiar, potentially lethal incident and to share our experience in its diagnosis and treatment.

\section{Case Report}

With IRB approval, we retrospectively reviewed charts of all NB patients at King Hussein Cancer Center (KHCC) between 2006 and 2015, and found 5 children who developed acute hemorrhagic shock prior to local surgical control. Children are treated according to our institutional protocol which incorporates 6 cycles of multi-agent chemotherapy followed by surgery, high dose chemotherapy with

\section{Journal of}

\section{Cancer Sciences}

\author{
Abeer Al-Diab ${ }^{1 *}$, lyad Sultan², Nesreen Faqih², \\ Rasha Deebajah², Hadeel Halalsheh ${ }^{2}$, Talib \\ Isamael $^{2}$, Mohammad M. Saleem ${ }^{1}$ and Khalil \\ Ghandour ${ }^{1}$ \\ ${ }^{1}$ Department of Surgery, King Hussein Cancer Center, Amman, Jordan \\ ${ }^{2}$ Department of Pediatrics, King Hussein Cancer Center, Amman, Jordan
}

*Address for Correspondence

Abeer Al-Diab, Department of Surgery, King Hussein Cancer Center, Queen Rania Street, P.O. Box 1269, Al-Jubeiha, Amman 11941, Jordan, Tel: +962-797310273, +962-6-5300460; Email: abeeraldiab@yahoo. com

Submission: 31 October 2017

Accepted: 11 December 2017

Published: 18 December 2017

Copyright: (c) 2017 Al-Diab A, et al. This is an open access article distributed under the Creative Commons Attribution License, which permits unrestricted use, distribution, and reproduction in any medium, provided the original work is properly cited.

stem cell rescue, radiotherapy, and cis-retinoic acid orally. Massive hemorrhage was defined as image-proven, intra-tumor bleeding that lead to hypotension.

\section{Results}

All 5 children were initially assigned to the high-risk group (Table 1). The primary tumor had been biopsied in 4 patients. The onset of hemorrhage was 7-10 days following cycle 1 of induction in all patients except in one patient (patient 3), where hemorrhage followed cycle 5 (Table 2). All patients had significant drop in their Hemoglobin (>2 gm/dl) and platelets. Their coagulation profiles were normal throughout the course of admission. All required massive blood and blood product's transfusion to restore hemodynamic parameters, replace blood loss, and maintain a stable hemoglobin level. In one patient (patient 1), chemotherapy doses were subsequently temporarily reduced for one cycle before resuming full dose.

Table 1: Demography, tumor biology, pathology, risk group, outcome.

\begin{tabular}{|c|c|c|c|c|c|}
\hline & Patient 1 & Patient 2 & Patient 3 & Patient 4 & Patient 5 \\
\hline Age & $12 \mathrm{~m}$ & $21 \mathrm{~m}$ & $54 \mathrm{~m}$ & $28 \mathrm{~m}$ & $132 \mathrm{~m}$ \\
\hline Primary & $\mathrm{L}$ adrenal & $\mathrm{L}$ adrenal & L adrenal & $\mathrm{R}$ adrenal & $\begin{array}{c}\mathrm{L} \\
\text { thoracoabdominal }\end{array}$ \\
\hline INPC & Poorly D & Poorly D & Not done & Poorly D & Poorly D \\
\hline MYCN & Amp & Amp & Not Amp & Lost & Amp \\
\hline $\begin{array}{l}\text { Bone } \\
\text { marrow }\end{array}$ & Negative & Negative & Positive & Negative & Positive \\
\hline Bone & Positive & Negative & Positive & Negative & Negative \\
\hline Risk group & HR & $\mathrm{HR}$ & HR & $\mathrm{HR}$ & $\mathrm{HR}$ \\
\hline $\begin{array}{l}\text { Pathology } \\
\text { at GTR }\end{array}$ & GNB & $\begin{array}{c}\text { Mature } \\
\text { neural } \\
\text { cells }\end{array}$ & None & GNB & Total necrosis \\
\hline $\begin{array}{l}\text { Overall } \\
\text { Outcome }\end{array}$ & $\begin{array}{c}\text { Relapse } \\
\text { Died } 21 \\
\mathrm{~m} \text { post } \\
\text { diagnosis }\end{array}$ & $\begin{array}{c}\text { Remission } \\
\text { Alive } 4 \\
\text { years }\end{array}$ & \begin{tabular}{|c|} 
Progression \\
Died 18 \\
m post \\
diagnosis
\end{tabular} & $\begin{array}{c}\text { Relapse } \\
\text { Died } 14 \\
\text { m post } \\
\text { diagnosis }\end{array}$ & $\begin{array}{l}\text { Remission } \\
\text { Alive } 4 \text { years }\end{array}$ \\
\hline
\end{tabular}

L: Left; R: Right; D: Differentiated; Amp: Amplified; HR: High Risk; Poor D: Poorly Differentiated; GNB: Ganglioneuroblastoma; GTR: Gross Total Resection. 
Table 2: Episodes of Hemorrhage, management and outcome.

\begin{tabular}{|c|c|c|c|c|c|}
\hline & Patient 1 & Patient 2 & Patient 3 & Patient 4 & Patient 5 \\
\hline $\begin{array}{l}\text { Onset/ } \\
\text { cycle }\end{array}$ & $1^{\text {st }}$ cycle & $1^{\text {st }}$ cycle & $5^{\text {th }}$ cycle & $1^{\text {st }}$ cycle & $1^{\text {st }}$ cycle \\
\hline Treatment & $\begin{array}{l}\text { Conserva } \\
\text { tive }\end{array}$ & $\begin{array}{l}\text { Conserva } \\
\text { tive }\end{array}$ & $\begin{array}{l}\text { Conserva } \\
\text { tive }\end{array}$ & $\begin{array}{c}\text { Conserva } \\
\text { tive }\end{array}$ & $\begin{array}{c}\text { Conserva } \\
\text { tive }\end{array}$ \\
\hline Episode 1 & Stopped & Stopped & Stopped & Stopped & \\
\hline Episode 2 & & Yes & & & \\
\hline Surgery & & Yes & & & Yes \\
\hline Outcome & Survived & Survived & Survived & Survived & Survived \\
\hline
\end{tabular}

All patients had abdominal pain, increased distention, severe pallor, and hypotension. CT scans with IV contrast showed increase in tumor size with presence of blood within the tumor and none in the peritoneum (Figure 1). Angiography was attempted in the first two cases and as it did not show any major blood vessel leak, it was not attempted in the remaining children.

In patient 5 , who had a thoraco-abdominal tumor, hemorrhage occurred in both compartments. Hemorrhage into the thorax however, remained active, which mandated operative control.

In patient 2 , a second episode of massive hemorrhage occurred during the same admission and despite massive transfusion of blood and crystalloids, hemorrhage persisted and the child remained hemodynamically unstable. The multidisciplinary team decision supported operative control of the hemorrhage.

All children survived massive hemorrhage. In the 2 children where surgical control was required (patient 2 and patient 5), the tumor contained viable poorly differentiated tumor cells. Assessment after cycle 5 showed tumor response by volume with partial remission $(\mathrm{N}=4)$ or complete remission $(\mathrm{N}=1)$. Histopathology of the respected tumor at the time of local control in the 4 patients with residual masses showed differentiated tumor cells in 3 and complete necrosis in another one. Similar to children with high-risk neuroblastoma treated by the same protocol, 2 patients only were long-term survivors while the other 3 relapsed and died later (Table 1).

\section{Discussion}

Approximately half of $\mathrm{NB}$ children at presentation have disseminated disease and are assigned for high-risk treatment [4]. Clinically silent hemorrhagic foci inside the primary have been described mainly in adrenal NB and at different ages 1,5 at initial presentation [5]. Such foci are frequently seen on repeat imaging at the time of local control. Hemorrhage has been reported in newborns mainly with adrenal cystic $\mathrm{NB}$, unilateral and bilateral where it remains contained within the capsule and is not massive to cause hypotension [6-9]. Such children are primarily managed surgically with excellent long term prognosis as the majority has favorable Shimada histology [10]. Massive hemorrhage and circulatory shock has been repeatedly ascribed to tumor rupture in newborns. The first report was in 1982 and rupture has been labeled spontaneous rather than related to birth trauma [11]. Massive hemorrhage has been reported during infancy where some presented following minor trauma 3 and tumor rupture was typically identified during laparotomy $[2,12]$. Immuneinduced tumor ischemia was cited as a cause for rupture in an infant with thoracic NB [13]. Outside this spectrum, massive hemorrhage
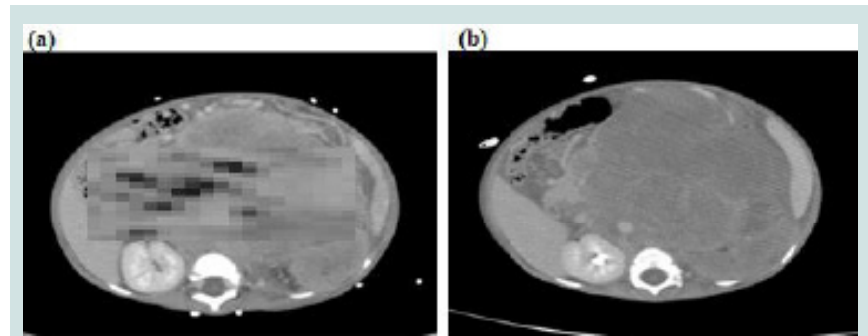

Figure 1: (a) Abdominal CT scan shows Left adrenal tumor at the time of diagnosis and (b) at the time of the event.

inside an intact tumor causing circulatory shock is an unexpected and previously unreported event. In our patients, it occurred during the induction phase of treatment. The presenting features were similar to those with tumor rupture.

Bleeding can be triggered by necrosis in a rapidly proliferating NB containing mainly un-differentiated or poorly differentiated cells. It occurs when the integrity of the endothelium is disrupted and the coagulative process is switched off. In massive hemorrhage it is thought that in response to chemotherapy, a large central area of viable and well-vascularized tumor cells dies [3]. Infarction of fragile small feeding vessels inside the center of the tumor can be an additional cause of massive bleeding. At the periphery, the tumor capsule remains intact, leading to large but contained blood loss. We did not identify a single major blood vessel leak on angiography in the first 2 cases. Although all children had low platelets count, an effect of chemotherapy, none had abnormal coagulation profile.

Intensive non-operative management was sufficient for the hemorrhage to stop in 4 of the 5 children. Surgical intervention was required on 2 occasions; in one child (patient 5), to control the initial continuing hemorrhage and in another child (patient 2) to control a second episode of massive bleeding. As complete tumor resection was not feasible the aim of the operation was to control hemorrhage through safe incomplete resection. A CT scan was used to map the zone of hemorrhage. Gross total resection of the remaining tumor was achieved at a second surgical session at the time of local control. There has been no hemorrhage-related mortality. Overall survival of this small group of children on high-risk protocol remains lower than in children with spontaneous tumor rupture [2]. Long term survival was possible when either total tumor necrosis or complete maturation was seen. Massive hemorrhage during induction chemotherapy might have been encountered but was not reported by collaborative groups. It remains a possibility that we receive patients with big size undifferentiated or poorly differentiated tumor cells that are more likely to bleed when treated with chemotherapy.

\section{Conclusion}

This report remains a retrospective analysis of a small number of children. Nevertheless, massive hemorrhage inside NB tumor can occur during initiation of chemotherapy. Intensive resuscitation and expectant management pending spontaneous arrest of hemorrhage has been sufficient in the majority of instances. Surgical intervention however, remains an option in continuing hemorrhage. The zero mortality rates related to this incident, one can safely conclude that it has no effect on the overall survival. 
Citation: Al-Diab A, Sultan I, Faqih N, Deebajah R, Halalsheh H, et al. Massive Intra-Tumor Hemorrhage during Induction Chemotherapy in Neuroblastoma: A Case Series Report. J Cancer Sci. 2017;4(1): 3.

ISSN: $2377-9292$

\section{References}

1. Hiorns MP, Owens CM (2011) Radiology of neuroblastoma in children. Eur Radiol 11: 2071-2081.

2. Honda S, Miyagi H, Minato M, Kubota KC, Okada T (2012) Hemorrhagic shock due to spontaneous rupture of adrenal neuroblastoma in an infant. J Pediatr Hematol Oncol 34: 635-637.

3. Normand C, Leblond P, Mazingue F, Nelken B, Defachelles AS, et al. (2006) A case of adrenal haemorrhage after minor trauma in a young child: think of neuroblastoma. European J Pediatr Surg 16: 365-368.

4. Alexander F (2000) Neuroblastoma. Urol Clin North Am 27: 383-392.

5. Guerrisi A, Marin D, Baski M, Guerrisi P, Capozza F, et al. (2013) Adrena lesions: spectrum of imaging findings with emphasis on multi-detector computed tomography and magnetic resonance imaging. J Clin Imaging Sci 3: 61

6. Duzovali O, Ozer C, Turhan AH, Arslankoylu AE, Yilgor E, et al. (2005) Bilateral adrenal cystic neuroblastoma with massive hepatomegaly and intracystic hemorrhage. Pediatr Blood Cancer 44: 525-526.
7. Lee SY, Chuang JH, Huang CB, Hsiao CC, Wan YL, et al. (1998) Congenital bilateral cystic neuroblastoma with liver metastases and massive intracystic haemorrhage. Br J Radiol 71: 1205-1207.

8. Cassady C, Winters WD (1997) Bilateral cystic neuroblastoma: Imaging features and differential diagnoses. Pediatr Radiol 27: 758-759.

9. Pinarli FG, Danaci M, Tander B, Dagdemir A, Diren B, et al. (2004) Bilateral adrenal cystic neuroblastoma with superior vena cava syndrome and massive intracystic haemorrhage. Pediatr Radiol 34: 746-749.

10. Kozakewich HP, Perez-Atayde AR, Donovan MJ, Fletcher JA, Estroff JA, et al. (1998) Cystic neuroblastoma: emphasis on gene expression, morphology and pathogenesis. Pediatr Dev Pathol 1: 17-28.

11. Brock CE, Rickets RR (1982) Hemoperitoneum from spontaneous rupture of neonatal neuroblastoma. Am J Dis Child 136: 370-371.

12. Meersman A, Wojciechowski $M$, Vaneerdeweg $W$, Jorens $P$, Michiels $E$, et al. (2008) Acute retroperitoneal hemorrhage and shock as presenting signs of neuroblastoma in an infant. Pediatr Emerg Care 24: 37-38.

13. Rath R, Touloukian RJ (1970) Infarction of a mediastinal neuroblastoma with hemorrhagic pleural effusion. Ann Thorac Surg 10: 552-555 